\title{
Characteristics and influence of green tide drift and dissipation in Shandong Rongcheng coastal water based on remote sensing
}

\author{
Dongxue $\mathrm{Li}^{\mathrm{a}, \mathrm{b}}$, Zhiqiang Gao ${ }^{\mathrm{a}, *}$, Debin Song ${ }^{\mathrm{a}, \mathrm{b}}$, Weitao Shang ${ }^{\mathrm{a}}$, Xiaopeng Jiang ${ }^{\mathrm{a}}$ \\ ${ }^{a}$ Yantai Institute of Coastal Zone Research, Chinese Academy of Sciences, Yantai, 264003, China \\ ${ }^{\mathrm{b}}$ University of Chinese Academy of Sciences, Beijing, 100049, China
}

\section{A R T I C L E I N F O}

\section{Keywords:}

Green tide

MODIS

Gaofen-1

Rongcheng coastal water

Drift

Dissipation characteristics

\begin{abstract}
A B S T R A C T
Green tides in the Yellow Sea have occurred in large-scale blooms since 2007. Originating in the southern Yellow Sea and drifting northward continuously, these green tides have severely affected the coastal ecological environment. To analyze the influence of green tides on marine aquaculture in the Rongcheng coastal water (the northernmost sea area influenced by green tide), we used the Moderate Resolution Imaging Spectrometer (MODIS), GaoFen-1 (GF-1) satellite imagery and the sea surface wind (SSW) data. We also used field investigation to analyze the drift trajectory, drift speed, dissipation speed and distribution density of green tides. The results show that the main body of a green tide will drift northeast and continue in this direction after crossing the Rongcheng Chengshanjiao coastal water. Between 2013 and 2018, the drift speeds of green tides to the north of this area were within $1-5 \mathrm{~km} / \mathrm{d}$, the drift speed in the east-west direction was $0.3-4 \mathrm{~km} / \mathrm{d}$, and the interannual difference was not significant. The dissipation speed of the green tide in the Rongcheng Sea is generally within the range of $1-5 \mathrm{~km}^{2} / \mathrm{d}$ and shows little interannual difference. The distribution density in the southern area of Rongcheng is the highest, ranging from $3 \%$ to $7 \%$. The area with the highest frequency of influence is also the area with the greatest distribution density of green tides, and disasters are most severe here. A reasonable collection area is proposed, based on the above analysis. This research provides the basis for understanding the characteristics of green tides in the dissipation phase, and the prevention and control methods of green tide disasters in the Rongcheng coastal water.
\end{abstract}

\section{Introduction}

Green tides are a type of marine ecological disaster caused by rapid reproduction of green macroalgae, occurring in coastal areas around the world (Blomster et al., 2002; Merceron et al., 2007). Large-scale blooms of green tide have occurred in the Yellow Sea from May to August every year since 2007. They are caused by the floating Ulva prolifera seaweed (Zhao et al., 2013, 2015) and often become attached to hard objects (Geng et al., 2015). The rapid expansion of the Porphyra aquaculture at the Jiangsu Shoal in the southern Yellow Sea not only provides favorable conditions for the attachment and growth of green tide algae, but also for its northward drift (Liu et al., 2010, 2013; Zhang et al., 2017). In April every year, with the harvest of the last round of Porphyra seaweed, large quantities of green tide algae are removed from the aquaculture raft scopes, and abandoned on the beach (Zhang et al., 2018). This algae reenters the sea via the tide, where it rapidly grows and accumulates, eventually drifting northward under the influence of sea surface circulation (Son et al., 2015). This can cause disasters along the coasts of Qingdao, Yantai and Weihai (Song et al., 2017; Cao et al., 2019).

During the outbreak in the Yellow Sea, the green tide covered an area of more than $1000 \mathrm{~km}^{2}$, which makes it the largest green tide disaster in the world (Zhou et al., 2015). With the increasing impact of human activities and climate change on the marine environment, the impact of green tides on the sea area continues to expand. This poses a serious threat to the sustainable development of aquaculture, human health and marine ecological security in coastal areas (Ye et al., 2011; Yu and Liu, 2016). For example, by producing toxins, damaging gill tissue of marine organisms, obstructing routes, and changing the physical and chemical environment of the water body, green tide disasters have become a global ecological problem.

Due to its advantages of a large observation time span, wide observation range, and easy access to data, satellite remote sensing is one of the most effective tools for the dynamic monitoring of green tides (Gu et al., 2011; Qiu and Lu, 2015). Through satellite observation, researchers have analyzed the green tide drift trajectory and the inter-

\footnotetext{
" Corresponding author.

E-mail address: zqgao@yic.ac.cn (Z. Gao).
} 


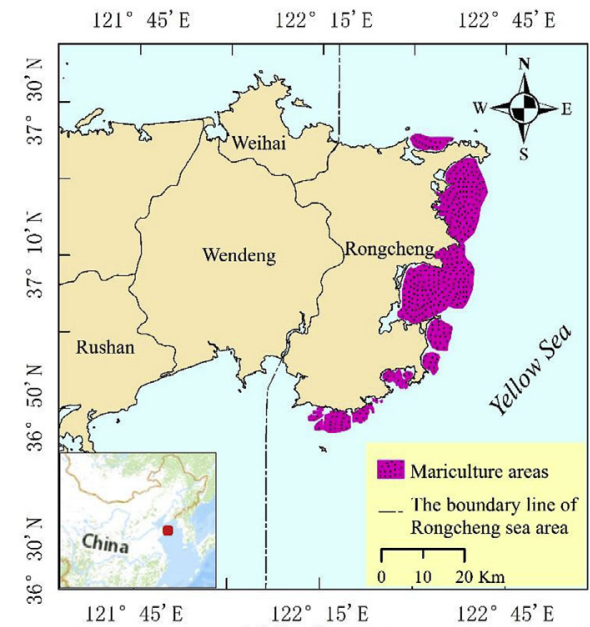

(a) Study area

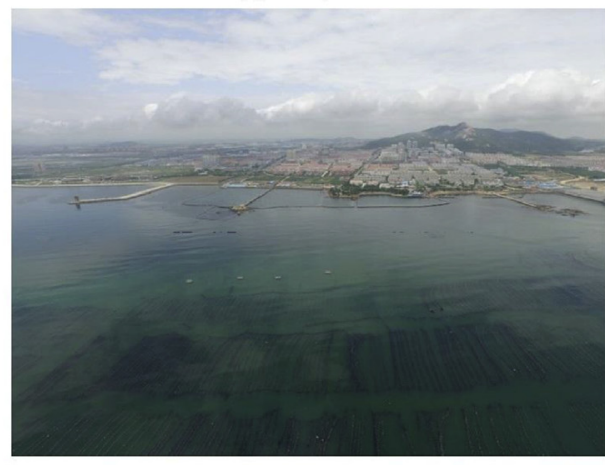

(c) UAV image in the mariculture areas

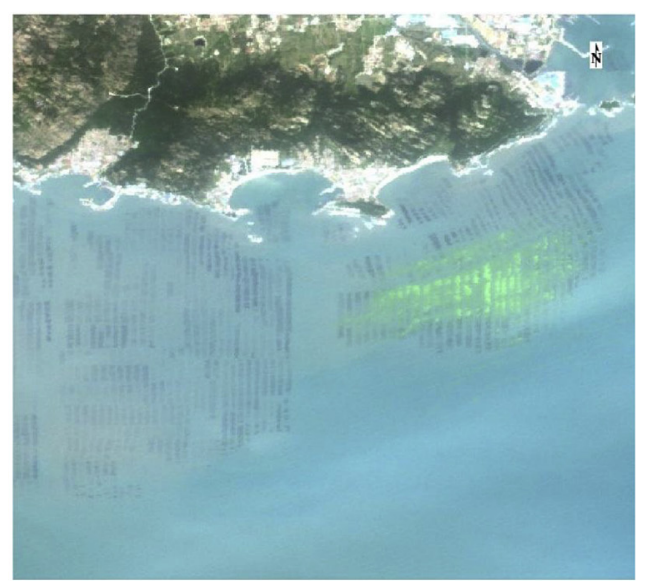

(b) GF-1 image in the mariculture areas

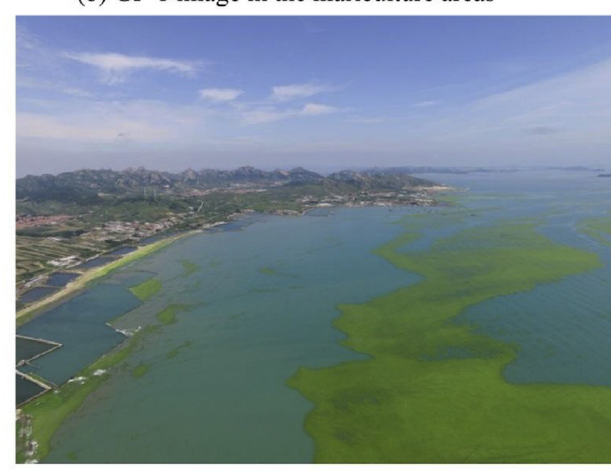

(d) UAV image of green tide

Fig. 1. (a) The study area. (b) The $16 \mathrm{~m}$ resolution true color GF-1 satellite image of mariculture areas in the study area, acquired on 20 July 2017. (c) and (d) Unmanned aerial vehicle (UAV) images of mariculture areas in the study area, taken by our field team on 4-7 July 2016. In (b), (c) and (d), the dark strip in the sea water is the mariculture area, and the green patches are green tide algae. (For interpretation of the references to color in this figure legend, the reader is referred to the Web version of this article.)

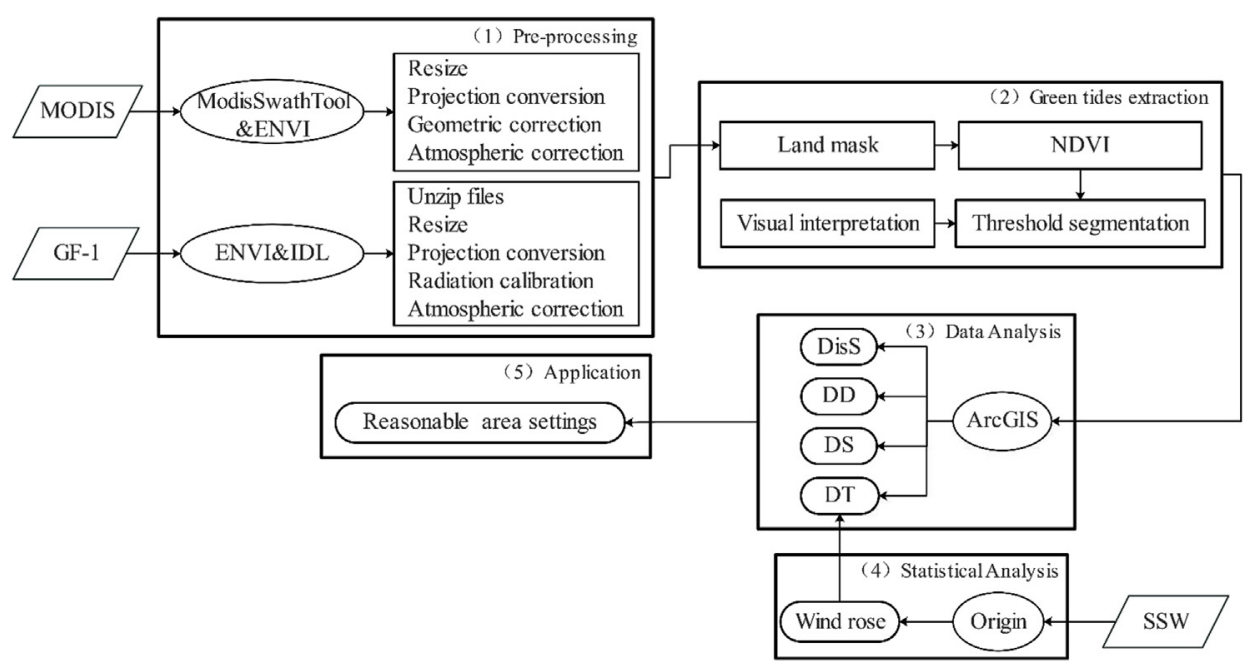

Fig. 2. Flow chart. (1) Pretreatment process: batch clipping, projection conversion, geometric correction and atmospheric correction of downloaded satellite images. Radiation calibration of GF-1 image is needed before atmospheric correction. (2) Extraction of green tides information: firstly, land mask is needed to eliminate the disturbance of land vegetation. NDVI is then calculated, and the threshold is adjusted by artificial visual interpretation to extract green tide patches. (3) Data analysis: DisS - dissipation speed, DD - distribution density, DS - drift speed, DT - drift trajectory. ArcGIS measurement tools, area statistics tools, and drawing tools were used to analyze the above items. (4) Statistical analysis: Origin 9.1 was used to draw the wind roses, and the wind direction and speed are counted. (5) Application: based on the above analysis of dissipation speed, distribution density, drift speed and drift trajectory, a reasonable collecting area for green tides in aquaculture areas is determined. (For interpretation of the references to color in this figure legend, the reader is referred to the Web version of this article.)

annual variation in the Yellow Sea (Keesing et al., 2011). The daily average drift speeds of green tides in the Jiangsu Redial Sandbanks and the southern coastal waters of Rushan have been documented (Cui et al., 2012; Harun-Al-Rashid and Yang, 2018); the coverage area in the Yellow Sea during different periods were analyzed (Cui et al., 2018; Cao et al., 2019); and the general dissipation process of the green tide has been described (Jin et al., 2018). Much of this research makes use of the Moderate Resolution Imaging Spectrometer (MODIS) satellite, with its characteristic wide coverage area and long time span. The GaoFen-1 (GF-1) satellite is more advantageous for the monitoring of green tides with small areas (Zheng et al., 2016; Gao et al., 2017), because of its high spatial resolution and high revisit period.

It is now known that early-stage collecting campaigns may be important for controlling the expansion of green tides (Lotze et al., 1999; Xing et al., 2018). For key protected areas like mariculture, collecting is also necessary during the dissipation phase of a green tide. Understanding the characteristics of green tides is essential for collecting work, but little is known about the details of green tides in Rongcheng coastal waters. Such details include the drift trajectory, drift speed, dissipation speed, distribution density, and the influence on marine aquaculture in this area. In this work, MODIS and GF-1 satellite data and sea surface wind (SSW) data are used to explore the drift trajectory, 


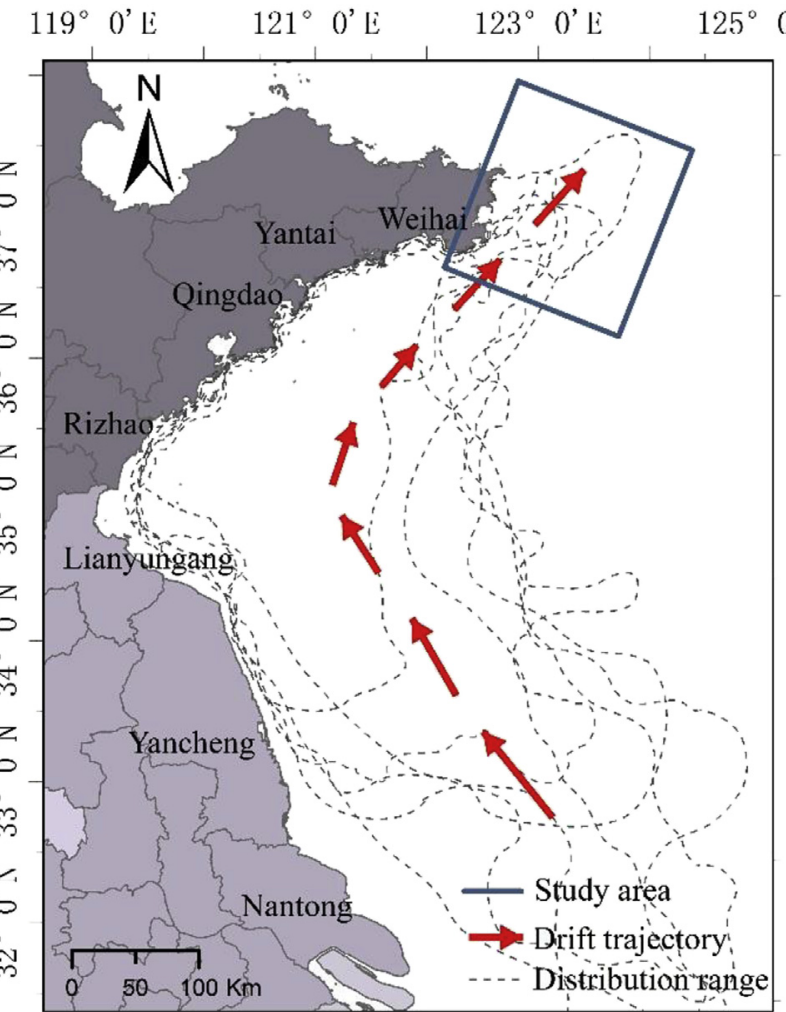

Fig. 3. Green tide drift trajectory and distribution scope from 2013 to 2018. The blue box represents the study area of this paper. Drift trajectory represented by red arrows, indicating the general direction of drift, drawn from the front of green tides. The gray dash lines indicate the range of green tide distribution in each year. (For interpretation of the references to color in this figure legend, the reader is referred to the Web version of this article.)

drift speed, dissipation speed, and distribution density of green tides in Rongcheng coastal water. These characteristics are then used to analyze the influence of green tides in Rongcheng coastal water, and propose a reasonable collecting area.

\section{Data and methods}

\subsection{The study area}

The study area, located at the easternmost end of Shandong Peninsula, belongs to the coastal sea area of Rongcheng city, which is well known as the Hometown of kelp in China. The corresponding latitude and longitude range are approximately $122^{\circ}-123^{\circ} 15^{\prime} \mathrm{E}, 36^{\circ}-37^{\circ} 40^{\prime}$ $\mathrm{N}$, as illustrated in Fig. 1. This area lies in the north temperate continental monsoon climate and sea in this area is fertile, with moderate transparency, smooth water flow, and only slight temperature variation, making it highly suitable for the growth of Laminaria japonica (kelp). The aquaculture area is about $100 \mathrm{~km}^{2}$, and the annual yield of fresh kelp is about 450,000 tons. The aquaculture area and yield both rank first in China. In addition, there is about $400 \mathrm{~km}^{2}$ of other mariculture areas, such as fish, shrimp, sea cucumber and shellfish. Since the large-scale blooms of green tide in 2007, there has been green tide algae distributing in the Rongcheng coastal water, from late July to early August, every year (Xinhua-News-Agency, 2015; Baijiahao, 2017; Marine-Environmental-Protection-Department-of-North-China-Sea-

Branch-of-State-Oceanic-Administration, 2018). The decomposition of Ulva prolifera consumed dissolved oxygen, changed the water quality, and affected the marine aquaculture of kelp, fish, shrimp, sea cucumber and shellfish. The government has monitored the green tide, and water quality of the sea area and then carried out collecting work every year.

\subsection{Dataset sources}

In this study, satellite data was collected for the period May to September in the years 2013-2018, from the GF-1 WFV (abbreviated as GF-1) data provided by the China Centre for Resources Satellite Data and Application (http://218.247.138.119:7777/DSSPlatform/ productSearch.html), and MODIS (TERRA/AQUA) data provided by the National Aeronautics and Space Administration (NASA) (https:// ladsweb.modaps.eosdis.nasa.gov/search/). WFV is a $16 \mathrm{~m}$ resolution multi-spectral camera mounted on the GaoFen-1 satellite. MODIS is a medium-resolution imaging spectrometer mounted on the Terra and Aqua satellites, with a maximum spatial resolution of $250 \mathrm{~m}$. The MODIS (MOD02QKM/MYD02QKM) images are mainly adopted to extract the overall distribution of the green tide, and the GF-1 images are mainly adopted to analyze the drift and dissipation characteristics of small-scale green tides.

The wind data in this paper was downloaded from the NASA remote sensing system data website and the SSW data, with a resolution of $25 \mathrm{~km}$ at a sea surface height of $10 \mathrm{~m}$, was acquired by the Advanced Scatterometer (ASCAT).

\subsection{Data processing}

In this study, 50 MODIS images and 21 GF-1 images were selected and used for green tide algae extraction. Because pre-processing involves a large number of images, batch processing tools were adopted for the image projection conversion, geometric correction and radiometric calibration. This process is illustrated in the flow chart of Fig. 2. The reflectance of green tide water is high in the near-infrared band, but low in the red light band. The reflectance of normal sea water in the red light and near-infrared bands is equivalent, which causes the Normalized Difference Vegetation Index (NDVI) to be relatively high in green tide accumulation areas. It can therefore be adopted to distinguish between green tide water and normal sea water ( $\mathrm{Hu}$ and $\mathrm{He}$, 2008; Cui et al., 2012). In the equation $N D V I=\frac{\left(\rho_{N I R}-\rho_{R}\right)}{\left(\rho_{N I R}+\rho_{R}\right)}$ (Rouse et al., 1974), $\rho_{N I R}$ is the near-infrared reflectance, and $\rho_{R}$ is the red light reflectance. The information regarding Ulva prolifera, extracted through the method proposed in this paper, was verified by comparing it to data from the Green tide bulletin in North China sea issued by the North China Sea Branch of the State Oceanic Administration from 2013 to 2018 (Marine-Environmental-Protection-Department-of-North-China-SeaBranch-of-State-Oceanic-Administration, 2018). The reliability of the data was further validated through our project team's field survey of the Rushan-Rongcheng coast, in 2016 and 2018. The extracted green tide data was then analyzed in terms of area, location and distance, using ArcGIS tools. The wind data was analyzed using Origin 9.1 (Fig. 2).

\section{Results analysis}

\subsection{Analysis of green tide drift trajectory and main influencing factors in Rongcheng coastal water}

\subsubsection{Green tide drift trajectory in Rongcheng coastal water}

Through analysis of satellite images from 2013 to 2018, it is clear that all green tides originated offshore of the Jiangsu shoal, and then drifted to the north. The corresponding drift trajectories for green tides, between 2013 and 2018, are illustrated as red arrows in Fig. 3. These arrows indicate the general direction of green tide drift, drawn from the front of the green tide. The green tides arrived in Shandong Peninsula coastal water from the end of May to the beginning of June, followed by the arrival of the large-scale green tides. The green tides that did not go ashore would drift to the north, arriving in Rongcheng coastal water from the end of June to the beginning of July, with the average influence period being about one month. The maximum sea area influenced by a green tide reached up to thousands of square kilometers. Over the 

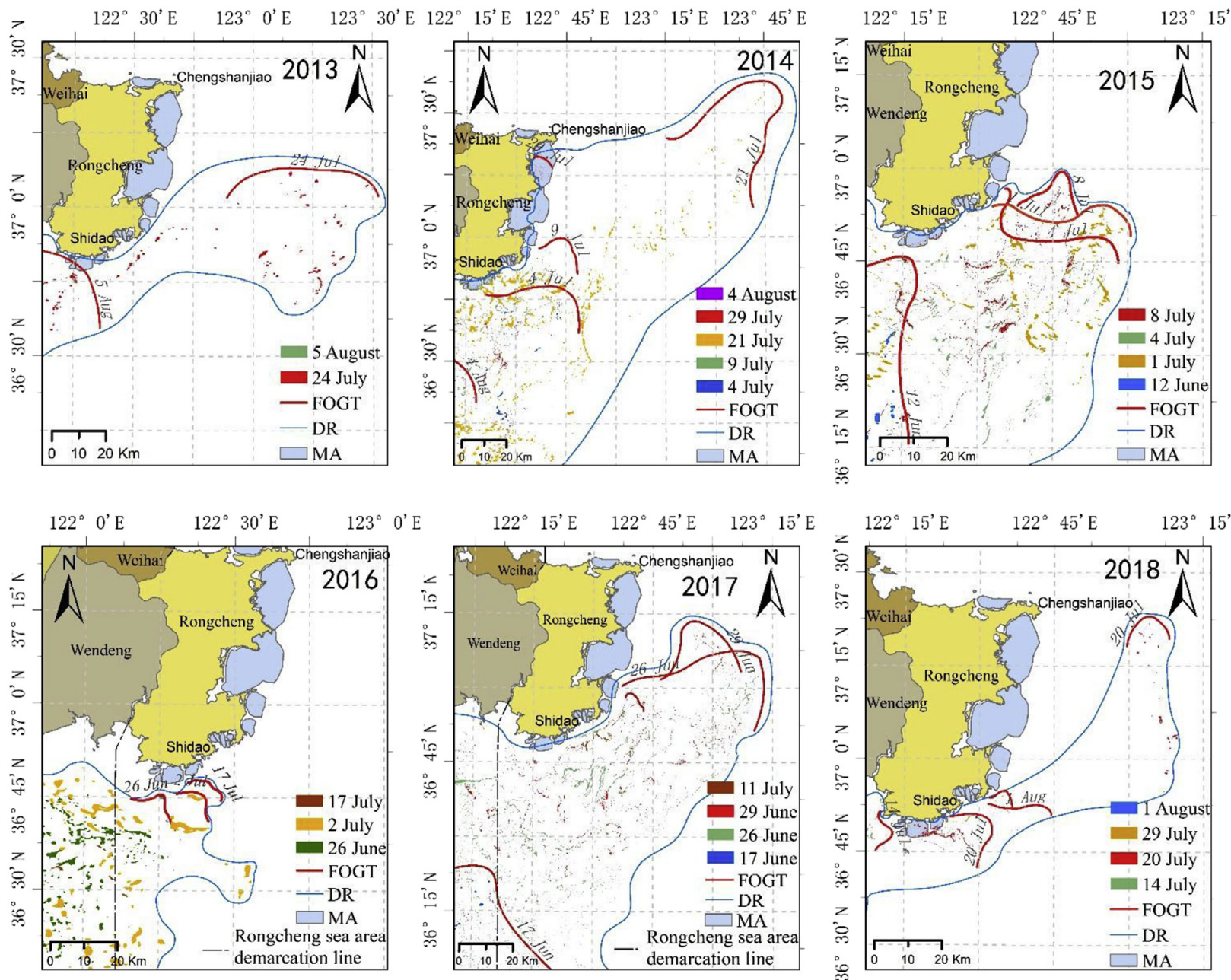

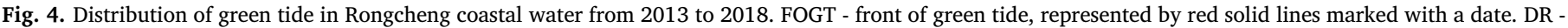

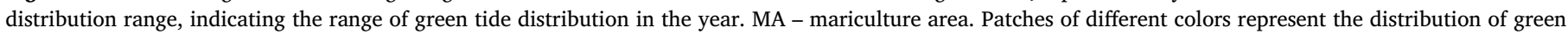
tides on different dates. (For interpretation of the references to color in this figure legend, the reader is referred to the Web version of this article.)

years, green tides would first reach the Rongcheng Shidao coastal sea area, as shown in Fig. 4, and would then continue to drift towards the northeast. Although a green tide may drift south in the short term, the overall long-term drift was to the northeast. The northernmost location reached by a green tide was $123.876^{\circ} \mathrm{E}, 37.662^{\circ} \mathrm{N}$, in 2014 , by which point the green tide had dispersed to form small patches. Having reached its northmost location, a green tide would gradually disappear on the sea surface, from north to south, due to its own growth cycle and the external environment. As observed from satellite images, it was only in 2014 that a green tide crossed the Rongcheng Chengshanjiao coastal waters, and drifted to the northern Yellow Sea area. The drift direction in this case was still northeast, which is consistent with the drift trajectory of Rongcheng coastal water, tracked by buoys from June to August in 2012 (Bao et al., 2015). Thus it is clear that green tides in this area have been mainly drifting in a northeast direction.

\subsubsection{Main influencing factors of green tide drift trajectory}

The drift of green tide in the Rongcheng coastal water was mainly influenced by the wind and the sea surface circulation. Fig. 5 depicts the wind direction and wind speed frequency statistical map for the range of $36-38^{\circ} \mathrm{N}, 122-124^{\circ} \mathrm{E}$. As we can see from Figs. 4 and 5 , the drift trajectory of green tides was closely related to wind direction and speed. Under the main influence of the north wind, the green tide would drift to the north for a greater distance in 2014, 2017 and 2018. Although the frequency and wind speed of the western component appear slightly larger than that of the east component, the green tide, as a whole, would still drift to the east, due to the mesoscale anti-cyclone vortex in the Qingdao-Shidao offshore region (Wei et al., 2011). The residual surface circulation in the southern coastal area of Shandong Peninsula points to the northeast all year round, forcing any green tide arriving in Rongcheng coastal water to drift to the northeast alongside Rongcheng Shidao. When the frequency and wind speed of the western component are large, the influence of the wind is greater than that of sea surface circulation, and green tides will drift a shorter distance towards the northeast, and will not cross $123^{\circ} \mathrm{E}$ in 2016 .

Based on the above analysis, green tides mainly drifted from the Qingdao-Rushan-Rongcheng coastal sea area, and crossed the Rongcheng Shidao coastal water. Under the main influence of the wind and sea surface circulation, green tides would drift to the northeast, and continue to drift to the northeast after they had crossed the Rongcheng Chengshanjiao coastal water.

\subsection{Analysis of green tide drift speed in Rongcheng coastal water}

Fig. 6 shows the contours of clear and visible green tides, with adjacent dates, extracted from GF-1 satellite images. To calculate drift distance for each contour, distances were measured between the furthest positions north and south, and the furthest positions east and west. The screened image dates are separated by $3-5$ days (see Table 1 ). During this time, the green tide patches in the southeast of the Rongcheng coastal water were distributed between $36^{\circ} 45^{\prime} \mathrm{N}$ and $37^{\circ} 20^{\prime} \mathrm{N}$ and $122^{\circ} 35^{\prime} \mathrm{E}$ and $123^{\circ} 20^{\prime} \mathrm{E}$. $\mathrm{U}$ is the average drift speed in the east-west 


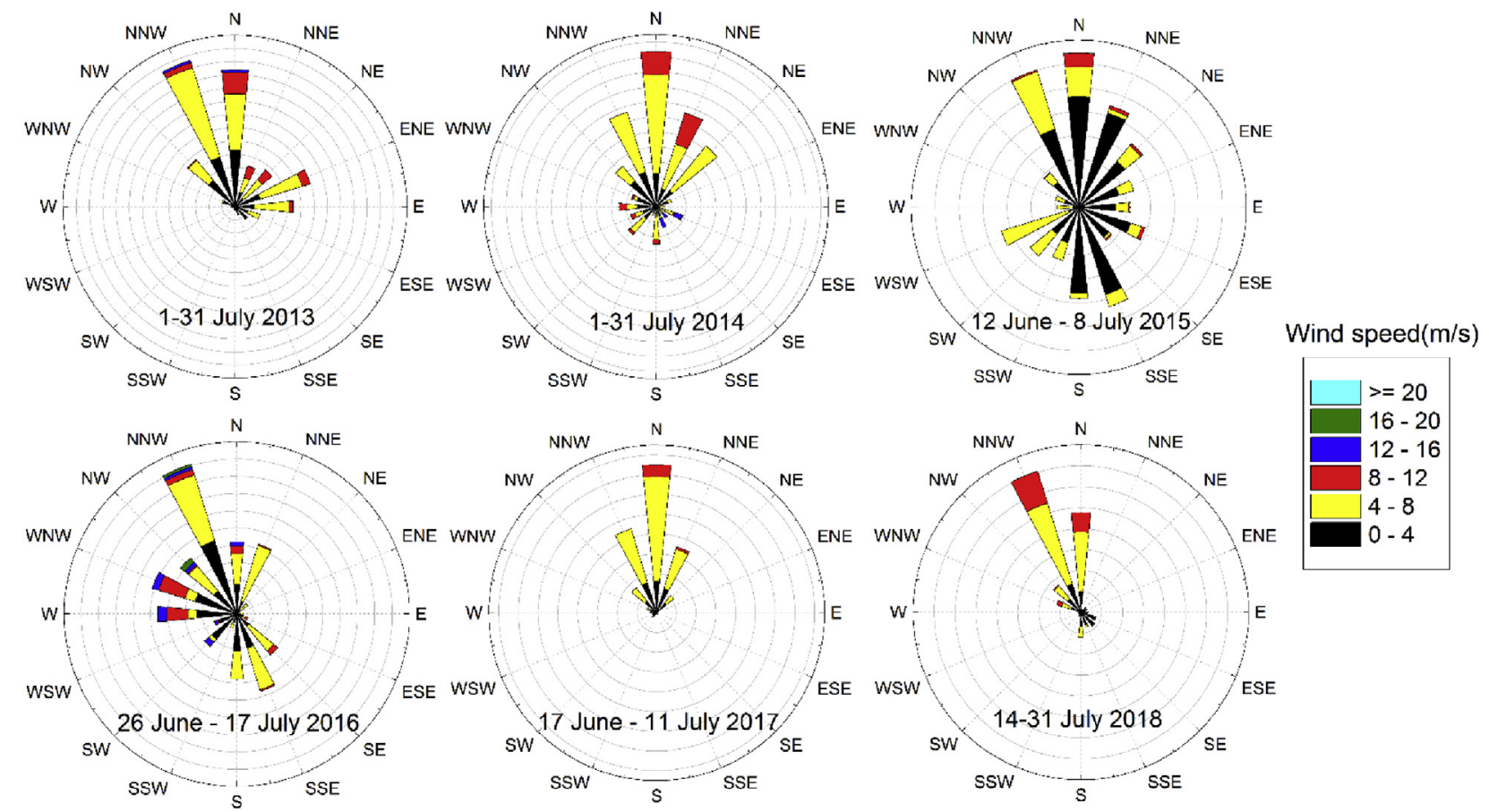

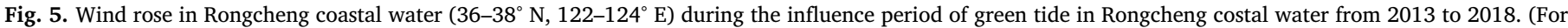
interpretation of the references to color in this figure legend, the reader is referred to the Web version of this article.)

direction, and is positive in the east direction, while $\mathrm{V}$ is the average drift speed in the north-south direction, and is positive in the north direction. Based on the ratio of the measurement values to interval days illustrated in Fig. 6, the average drift speed in 2014, 2015, 2017 and 2018 are shown in Table 1. Among them, the drift speed in 2015 represents the average from 1 July to 8 July, and the average drift speed from 1 July to 4 July is $U=-1.53 \mathrm{~km} / \mathrm{d}$ and $\mathrm{V}=-3.33 \mathrm{~km} / \mathrm{d}$, while the average drift speed from 4 July to 8 July is $U=-1.94 \mathrm{~km} / \mathrm{d}$ and $\mathrm{V}=4.23 \mathrm{~km} / \mathrm{d}$, which confirms that the drift speed of a green tide can fluctuate greatly within a short time period.

By observing the average drift speed of green tide fronts in this area over 3-5 days, in various years, it can be found that the drift speed to the north is in the range of $1-5 \mathrm{~km} / \mathrm{d}$, the drift speed in the east-west direction is in the range of $0.3-4 \mathrm{~km} / \mathrm{d}$, and the interannual difference between years is not significant.

\subsection{Analysis of green tide dissipation speed in the Rongcheng coastal water}

By the time that green tides reach the Qingdao coastal water, they have begun to dissipate (Zhang et al., 2013). As they continue to drift northward, the coverage area in the Yellow Sea is continuously decreasing. When they reach the Rongcheng coastal water, the coverage area first increases and then decreases, indicating that the drift speed is greater than the dissipation speed. In the late dissipation period, because the green tides in the Yellow Sea are continuously decreasing, those drifting to the Rongcheng Sea are also decreasing, which makes the dissipation speed greater than the drift speed, and eventually results in the green tides disappearing from the Rongcheng Sea surface.

Dissipation speed

$$
=\frac{\text { Maximumcoverageareaobserved }- \text { Coveragearealastobserved }}{\text { Interval Days }}
$$

Maximum coverage area observed is the largest coverage area of green tide observed in satellite images, Coverage area last observed is the last time coverage area of a green tide was observed in satellite images during its dissipation, Interval Days is the days between the two observations.
Table 2 shows the average dissipation speed of green tides from 2013 to 2018, by means of Eq. (1). While no suitable GF-1 satellite images were available for the 2013 and 2016 late dissipation periods, the dissipation speed calculated from MODIS images does not differ from the magnitude of other years. The dissipation speed from 9 July to 29 July 2014 by means of GF- 1 is $1.19 \mathrm{~km}^{2} / \mathrm{d}$, and the dissipation speed from 14 July to 21 July 2014 by means of MODIS is $0.09 \mathrm{~km}^{2} / \mathrm{d}$, which further indicates that there is little difference between the MODIS and GF-1 satellite monitoring accuracy. The dissipation of green tides is influenced by many factors, and the dissipation speed calculated by the above methods through satellite observation can provide a reference index for macroscopic monitoring of the characteristics of green tide dissipation in the specific sea areas, although it should be noted that the above results do not take the collecting of biomass into account.

The dissipation speed of green tides in Rongcheng coastal water between 2013 and 2018 is $1-5 \mathrm{~km}^{2} / \mathrm{d}$, and there is little difference in terms of interannual change. This value does not only reflect the dissipation speed of the green tide, but also includes the calculation of the green tide drifting to this area. It reflects the integral dissipation speed of the green tide, which has practical significance for estimating green tide collection.

\subsection{Analysis of mariculture disaster in the Rongcheng coastal water}

\subsubsection{Influence of green tides on mariculture areas}

The influence of green tides on the Rongcheng mariculture areas is illustrated in Fig. 7. The red area indicates that the sea area has been influenced by green tide over the years (AIA), which accounts for $12.8 \%$ of the total aquaculture area; the yellow area indicates that the sea area has been influenced by green tide only in the years 2014, 2015 and 2017 (OIA), which accounts for $82.1 \%$ of the total aquaculture area, and the blue area indicates sea areas that were not influenced by green tide over the years (NIA), which accounts for $5.1 \%$ of the total aquaculture area. The sea area was most severely affected in 2014 and 2017, which accounts for $94.9 \%$ and $23.5 \%$ of the total aquaculture area respectively. 

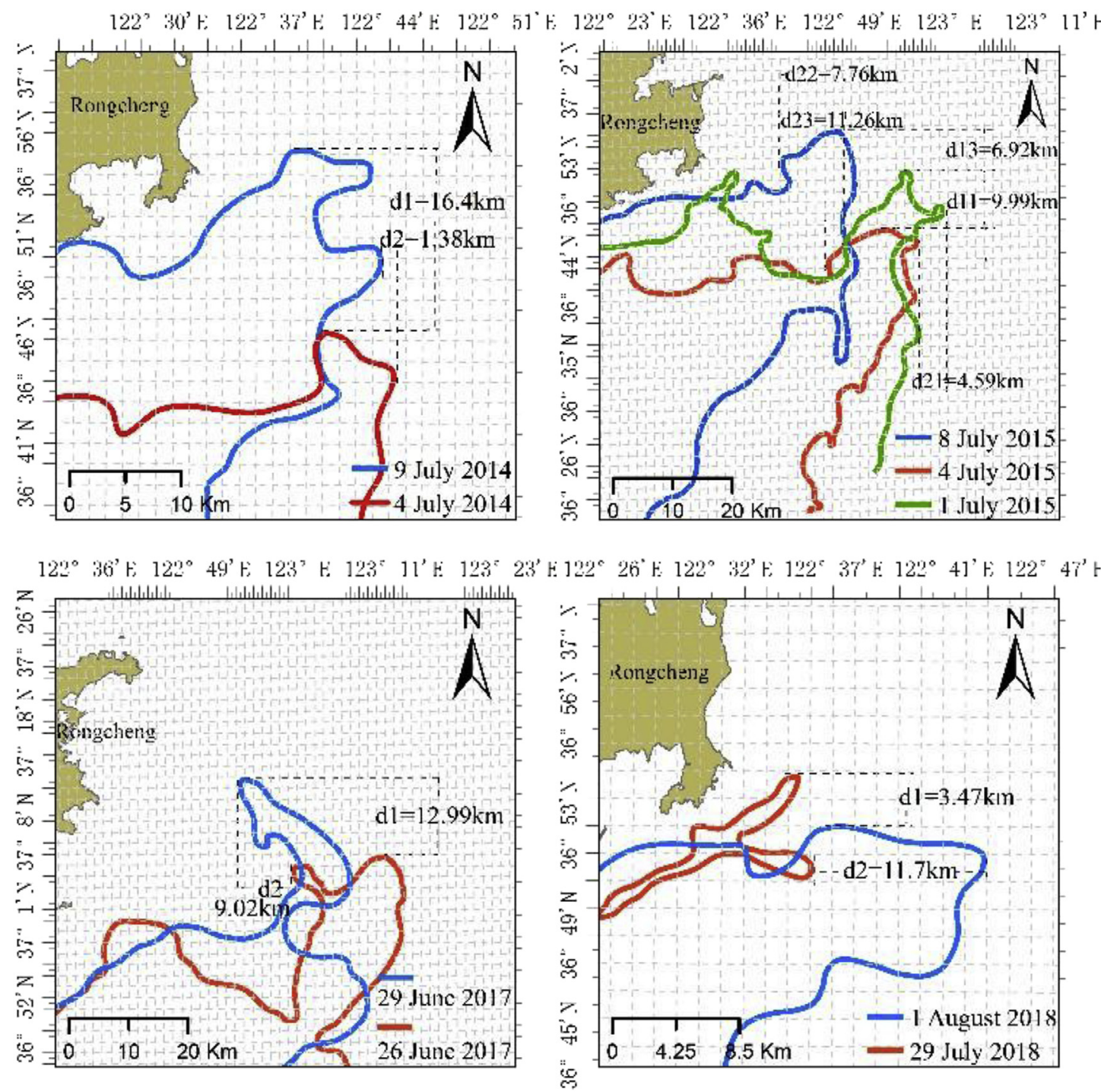

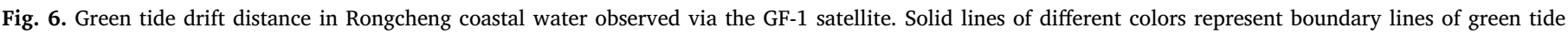

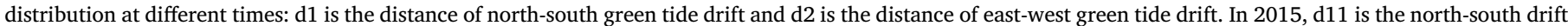

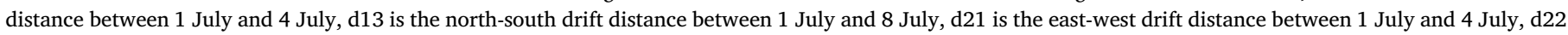

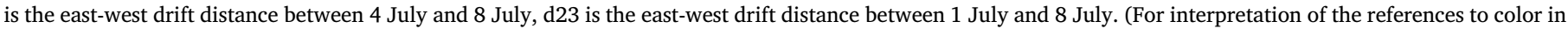
this figure legend, the reader is referred to the Web version of this article.)

Table 1

The average drift speed of the green tide.

\begin{tabular}{llll}
\hline Years & $\mathrm{U}(\mathrm{km} / \mathrm{d})$ & $\mathrm{V}(\mathrm{km} / \mathrm{d})$ & Image dates \\
\hline 2014 & 0.28 & 3.28 & 4 July and 9 July \\
2015 & -1.61 & 0.99 & 1 July, 4 July and 8 July \\
2017 & -3.01 & 4.33 & 26 June and 29 June \\
2018 & 3.9 & 1.16 & 29 July and 1 August \\
\hline
\end{tabular}

Table 2

The average dissipation speed of green tides from 2013 to 2018 by means of Eq. (1).

\begin{tabular}{lll}
\hline Years & Dissipation speed $\left(\mathrm{km}^{2} / \mathrm{d}\right)$ & Satellites \\
\hline 2013 & 3.83 & MODIS \\
2014 & 1.19 & GF-1 \\
2015 & 0.72 & GF-1 \\
2016 & 3.57 & MODIS \\
2017 & 4.78 & GF-1 \\
2018 & 1.26 & GF-1 \\
\hline
\end{tabular}

\subsubsection{Analysis of green tides distribution density in the Rongcheng coastal} water

The algae making up a green tide will have a different distribution density at different growth phases, in different sea areas. The Rongcheng coastal waters were divided into three regions, based on field investigations and satellite monitoring of green tide distribution, combined with coastline characteristics and the distribution of aquaculture areas. The three regions ( $a, b$ and $c$ ) are shown in Fig. 8. Distribution density is the ratio of coverage area to distribution area of a green tide. This was used to calculate the average density of green tides in the above three regions, from 2013 to 2018. Driven by wind and sea surface circulation, the green tide algae drift northward along the nutrient-rich offshore area of the Yellow Sea. In area a, the green tide algae first affects the Rongcheng mariculture areas, where the annual average distribution density is relatively high, at 5.3\%. Area b is large, and because the nutrient levels are relatively low due to kelp culture, the death rate of green tide algae is accelerated. The density is therefore lower than that of area a, with an annual average distribution density of $2.6 \%$. Area $\mathrm{c}$ is seldom affected by the green tide algae, and then usually only for a few days. The annual average distribution density is 


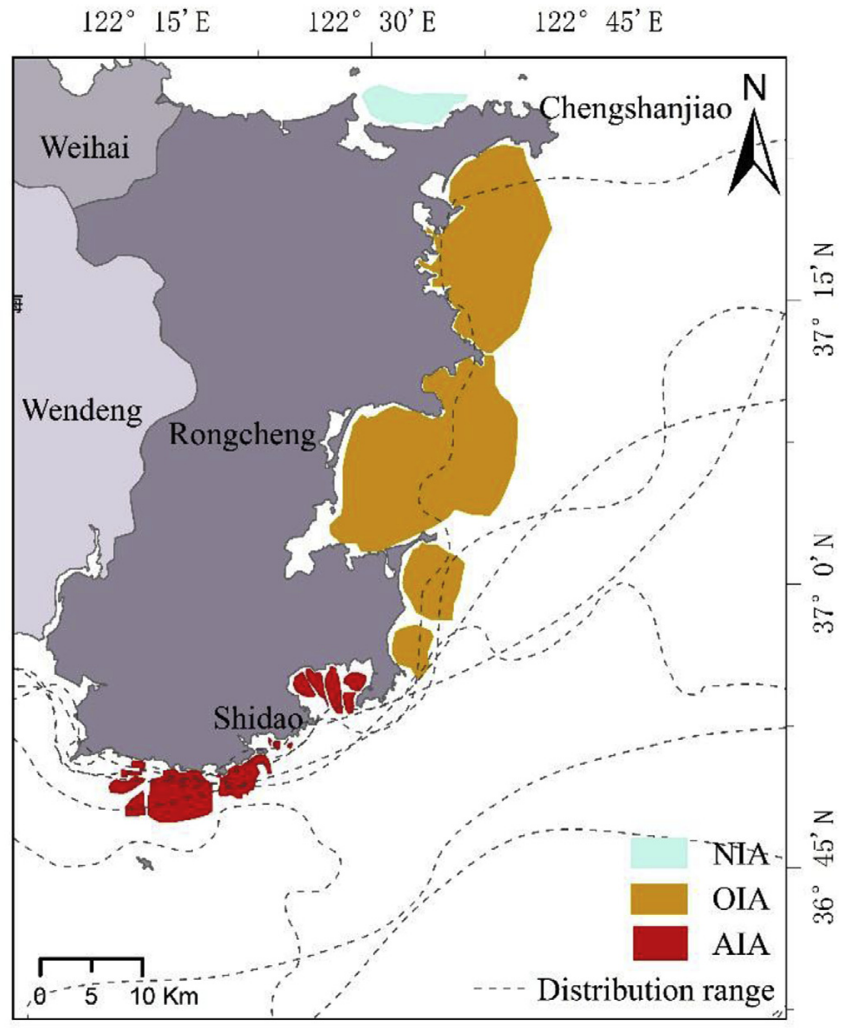

Fig. 7. Influence on Rongcheng mariculture areas from 2013 to 2018 . NIA refers to Never influenced areas, OIA refers to Occasionally Influenced Areas, AIA refers to Always Influenced Areas. The range of green tide distribution in each year, from 2013 to 2018, is indicated. (For interpretation of the references to color in this figure legend, the reader is referred to the Web version of this article.)

therefore much lower, at $1.8 \%$.

\section{Discussion}

\subsection{Understanding of green tide characteristics in Rongcheng coastal water}

Rongcheng coastal water is the northernmost area influenced by green tide in the Yellow Sea, although the influence scope and degree are less than that of Qingdao (Li et al., 2014; Liu et al., 2015). This area contains hundreds of square kilometers of aquaculture, and is located on the division line of the northern and southern Yellow Sea. The characteristics of green tides in this area therefore are of great significance to further understanding the features of the green tide dissipation phase, the prevention and control of green tide disasters in Rongcheng coastal water, and the threat of green tides to the northern Yellow Sea.

Few detailed studies have been conducted on the drift trajectory, drift speed, dissipation characteristics, and distribution density of green tides in the Rongcheng area. As found in this study, after reaching the Rongcheng coastal water, green tides mainly drift towards the northeast, which is slightly different from the integral drift direction of green tides south of the Rongcheng coastal water (Xing et al., 2011; Bao et al., 2015), although the main driving factors are still the wind and sea surface circulation (Qiao et al., 2011; Hu et al., 2018). Xing et al. (2018) analyzed the daily average drift speed of green tides in the whole Yellow Sea area, between May and June 2016, and found a velocity of about $4.5 \mathrm{~km} / \mathrm{d}$ (Xing et al., 2018), which is similar to the average northward drift speed of green tides in the Rongcheng coastal water. It is clear that for different periods, the northward drift speed of green tides in different sea areas is basically the same. In most studies,

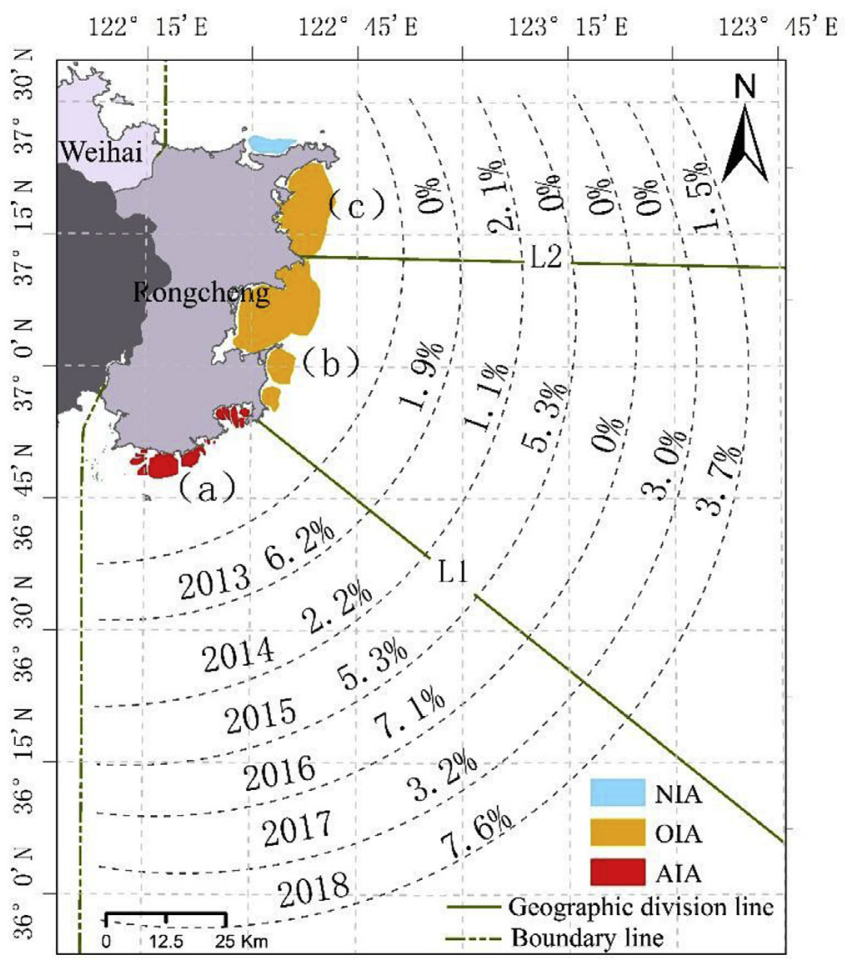

Fig. 8. Density distribution of green tides in Rongcheng coastal water from 2013 to 2018. NIA refers to Never Influenced Areas, OIA refers to Occasionally Influenced Areas, AIA refers to Always Influenced Areas. The three regions of a, $\mathrm{b}$ and $\mathrm{c}$ are artificially divided according to the influence of green tides over the years and the characteristics of the coastline. The green solid line is the division of three regions of $\mathrm{a}, \mathrm{b}$ and $\mathrm{c}$. The green dashed line is the boundary line of Rongcheng Sea area. The area between the northern boundary line of Rongcheng and the green solid line L1 is region a, the area between the green solid lines L1 and L2 is region b, and the area between the green solid line L2 and the southern boundary line of Rongcheng is region c. The percentages in the figure are the annual distribution densities of green tides in the three regions a, b and c, from 2013 to 2018. (For interpretation of the references to color in this figure legend, the reader is referred to the Web version of this article.)

dissipation and distribution density are mostly based on the overall analysis of the whole Yellow Sea area (Keesing et al., 2011). The dissipation speed and distribution density of green tides in the Rongcheng coastal water are specifically calculated in this paper, which is more instructive for regional collecting.

\subsection{Setting of the front collecting area in the Rongcheng coastal water}

The average influence period of green tides in the Rongcheng coastal water can reach about 30 days, and the distribution area can reach thousands of square kilometers. The floating green tide algae become stranded on the aquaculture rafts, where they shield the sea surface, limiting the photosynthesis of kelp (China-Aquaculture-Net, 2012) and thereby affecting the yield and quality thereof. For fish, shrimp, sea cucumber and shellfish aquaculture areas, a large quantity of green tide algae would reduce primary productivity, and indirectly influence the aquaculture and ecological environment in the sea area. The decay and decomposition of green tide algae during the dissipation phase consumes the dissolved oxygen in water, which would cause quantities of shellfish to die due to lack of oxygen (Le Luherne et al., 2016; Paumier et al., 2018).

The Weihai Government will organize nearly a thousand boats every year, and more than 100 people, for collecting thousands of tons of green tide algae (Sina, 2018). Whenever a large area of green tide 


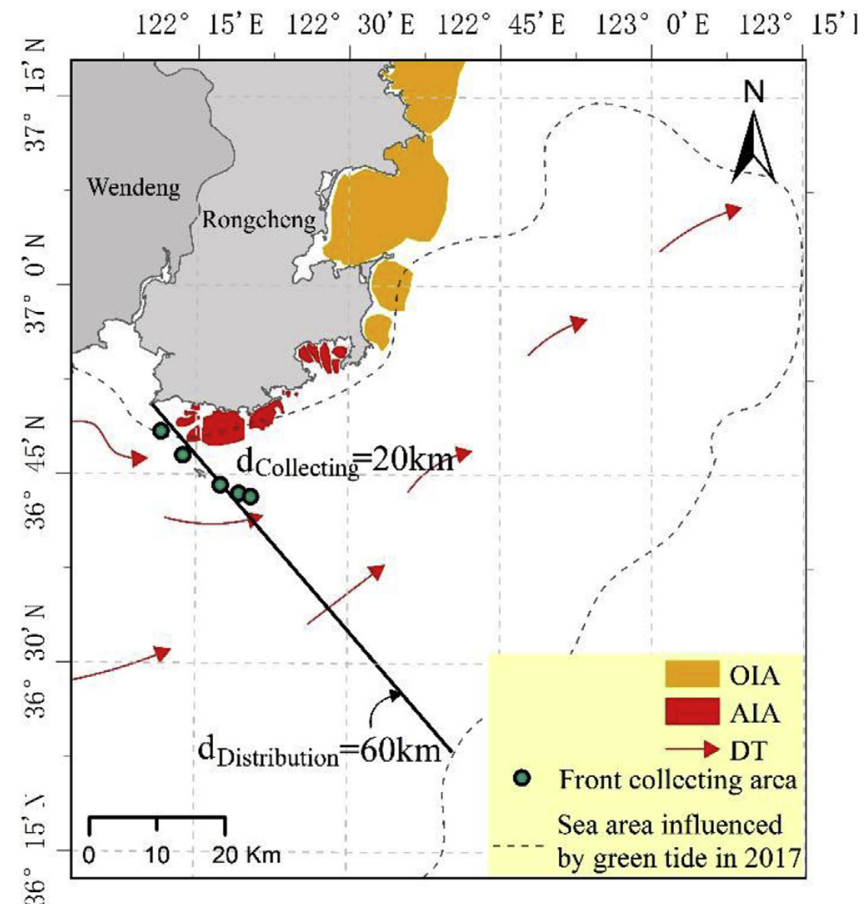

Fig. 9. Schematic map of front collecting area for green tides in Rongcheng coastal water. OIA refers to Occasionally Influenced Areas, AIA refers to Always Influenced Areas, DT refers to drift trajectory, represented by red arrows. The dashed line is the distribution range of the green tide in 2017. The green spot is the location of the collecting area. The black solid line is an extension line which is used to measure the width of the green tide distribution in the collecting area. $d_{\text {Distribution }}$ is the width of green tide distribution along the extension line of the 2017 collecting area. $\mathrm{d}_{\text {Collecting }}$ is the length of the collecting area. (For interpretation of the references to color in this figure legend, the reader is referred to the Web version of this article.)

arrives near the aquaculture area or shore, the government will organize the collecting work, which will focus on the green tide within 5 nautical miles $(9.26 \mathrm{~km})$ of the shore. This collecting strategy needs the support of large-scale and high-precision monitoring, and because the green tides mostly occur in small patches, the collecting area is relatively dispersed, and the efficiency is relatively low.

During the late dissipation phase, blocks of floating green algae are relatively easy to clean up. The analysis of the disaster area and distribution density of the green tide indicates that area $a$, shown in Fig. 8, has indeed suffered green tide disasters, and it has had a high distribution density over the years. Considering that the drift trajectory of the main body of the green tide is in the northeast direction, the collecting area was moved to the front collecting area as shown in Fig. 9.

The year of 2017 provides an example of a case where a green tide drifted over the collecting area. In such a situation, the rationality of the collecting area setting is analyzed, and the collecting distance is set to about $20 \mathrm{~km}$ (10.8 nautical miles). The process of calculating the collecting window is as follows:

$S_{\text {Rest }}=\frac{d_{\text {Collecting }}}{d_{\text {Distribution }}} * S_{\text {Total }}$

$T=\frac{S_{\text {Rest }}}{V_{\text {Dissipation }}}$

$S_{\text {Rest }}$ is the remaining area covered by green tide after collecting, $d_{\text {Collecting }}$ is the length of the collecting area, as shown in Fig. $9(20 \mathrm{~km})$, $d_{\text {Distribution }}$ is width of green tide distribution at collecting area when entering into the Rongcheng Sea on 26 June, as shown in Fig. 9 $(60 \mathrm{~km}) . S_{\text {Total }}$ is the coverage area of green tide when entering into the Rongcheng Sea on 26 June $\left(80.7 \mathrm{~km}^{2}\right.$. $T$ is the collecting window, while $V_{\text {Dissipation }}$ is the green tide dissipation speed in this period $\left(4.78 \mathrm{~km}^{2} / \mathrm{d}\right)$.

According to Eq. (2), $S_{\text {Rest }}$ can be obtained by multiplying the ratio of $d_{\text {Collecting }}$ to $d_{\text {Distribution }}$ by $S_{\text {Total }}$. In this case, the collecting window calculated by Eq. (3) is about 11 days. This calculation assumes that the green tide has a uniform distribution density, when in reality the green tide will be slightly more dense near the land, and the main body will drift to the northeast after having crossed the protection of the collecting area. Green tide will not stay within the collecting area all the time, so the actual collecting window will be less than 11 days. The above estimation is based on the $20 \mathrm{~km}$ distance of the collecting area. The specific collecting distance can be adjusted according to the actual situation of the green tide outbreak.

Through the analysis of drift trajectory, drift speed, dissipation speed, disaster situation, and distribution density of green tides in the Rongcheng coastal water, setting a reasonably narrow collecting area could shorten the collecting days, so that collecting efficiency can be improved. The specific prevention and control effect and implementation situation need to be combined with the actual operation to further confirm these ideas.

\section{Conclusion}

MODIS and GF-1 satellite images and SSW data are adopted in this paper, and are used to analyze the drift trajectory, drift speed, dissipation speed, disaster situation, and distribution density of green tides in Rongcheng coastal water from 2013 to 2018. These green tide characteristics assist in creating further understanding of the green tide dissipation phase, proposing a reasonable collecting area, and evaluating the threat of green tide disasters in the northern Yellow Sea.

\section{Acknowledgments}

This work was supported by the National Natural Science Foundation of China [41876107], NSFC-Shandong joint fund project [U1706219],Basic Special Program of Ministry of Science and Technology [2014FY210600],the Qingdao National Laboratory for Marine Science and Technology of China [2016ASKJ02]. We thank the U.S. NASA for providing MODIS and SSW data, and China Centre For Resources Satellite Data and Application for providing GF-1 data.

\section{References}

Baijiahao, 2017. There Are a Few Green Tide Influencing the Rushan, Wendeng and Rongcheng Offshore Sea Waters. 14 Jul 2017. https://baijiahao.baidu.com/s?id= $1571983213525637 \& w f r=$ spider\&for $=p c$ (In Chinese).

Bao, M., Guan, W.B., Yang, Y., Cao, Z.Y., Chen, Q., 2015. Drifting trajectories of green algae in the western Yellow Sea during the spring and summer of 2012. Estuar. Coast Shelf Sci. 163, 9-16. https://doi.org/10.1016/j.ecss.2015.02.009.

Blomster, J., Back, S., Fewer, D.P., Kiirikki, M., Lehvo, A., Maggs, C.A., Stanhope, M.J. 2002. Novel morphology in Enteromorpha (Ulvophyceae) forming green tides. Am. J. Bot. 89, 1756-1763. https://doi.org/10.3732/ajb.89.11.1756.

Cao, Y.Z., Wu, Y.C., Fang, Z.X., Cui, X.J., Liang, J.F., Song, X., 2019. Spatiotemporal patterns and morphological characteristics of Ulva prolifera distribution in the Yellow Sea, China in 2016-2018. Remote Sens. 11, 1-27. https://doi.org/10.3390/ rs11040445.

China Aquaculture Net, 2012. A Large Number of Raft Culture of Enteromorpha Prolifera Have Been Found in Xunshan Area, Rongcheng, Shandong Province, Which the Raft Aquaculture Is Seriously Influenced. 21 Jul 2012. http://www.shuichan.cc/news_ view-95938.html (In Chinese).

Cui, T.W., Liang, X.J., Gong, J.L., Tong, C., Xiao, Y.F., Liu, R.J., Zhang, X., Zhang, J., 2018. Assessing and refining the satellite-derived massive green macro-algal coverage in the Yellow Sea with high resolution images. ISPRS J. Photogrammetry Remote Sens. 144, 315-324. https://doi.org/10.1016/j.isprsjprs.2018.08.001.

Cui, T.W., Zhang, J., Sun, L.E., Jia, Y.J., Zhao, W.J., Wang, Z.L., Meng, J.M., 2012. Satellite monitoring of massive green macroalgae bloom (GMB): imaging ability comparison of multi-source data and drifting velocity estimation. Int. J. Remote Sens. 33, 5513-5527. https://doi.org/10.1080/01431161.2012.663112.

Gao, Z.Q., Xu, F.X., Song, D.B., Zheng, X.Y., Chen, M.S., 2017. Multi-resource data-based research on remote sensing monitoring over the green tide in the Yellow Sea. In: Remote Sensing and Modeling of Ecosystems for Sustainability XIV. Spie-Int Soc Optical Engineering, Bellingham. https://doi.org/10.1117/12.2271732. 
Geng, H.X., Yan, T., Zhou, M.J., Liu, Q., 2015. Comparative study of the germination of Ulva prolifera gametes on various substrates. Estuar. Coast Shelf Sci. 163, 89-95. https://doi.org/10.1016/j.ecss.2014.12.026.

Gu, X.F., Chen, X.F., Yin, Q., Li, Z.Q., Xu, H., Shao, Y., Li, Z.W., 2011. Stereoscopic remote sensing used in monitoring enteromorpha prolifra disaster in Chinese Yellow Sea. Spectrosc. Spectr. Anal. 31, 1627-1632. (In Chinese with English abstract). https:// doi.org/10.3964/j.issn.1000-0593(2011)06-1627-06.

Harun-Al-Rashid, A., Yang, C.S., 2018. Hourly variation of green tide in the Yellow Sea during summer 2015 and 2016 using geostationary ocean color imager data. Int. J. Remote Sens. 39, 4402-4415. https://doi.org/10.1080/01431161.2018.1457228.

$\mathrm{Hu}, \mathrm{C} ., \mathrm{He}$, M.X., 2008. Origin and offshore extent of floating algae in Olympic sailing area. Eos. Trans. Am. Geophys. Union 89, 302-303. https://doi.org/10.1029/ 2008EO330002.

Hu, P., Liu, Y.H., Hou, Y.J., Yi, Y.Q., 2018. An early forecasting method for the drift path of green tides: a case study in the Yellow Sea, China. Int. J. Appl. Earth Obs. Geoinf. 71, 121-131. https://doi.org/10.1016/j.jag.2018.05.001.

Jin, S., Liu, Y.X., Sun, C., Wei, X.L., Li, H.T., Han, Z., 2018. A study of the environmental factors influencing the growth phases of Ulva prolifera in the southern Yellow Sea, China. Mar. Pollut. Bull. 135, 1016-1025. https://doi.org/10.1016/j.marpolbul. 2018.08.035.

Keesing, J.K., Liu, D.Y., Fearns, P., Garcia, R., 2011. Inter- and intra-annual patterns of Ulva prolifera green tides in the Yellow Sea during 2007-2009, their origin and relationship to the expansion of coastal seaweed aquaculture in China. Mar. Pollut. Bull. 62, 1169-1182. https://doi.org/10.1016/j.marpolbul.2011.03.040.

Le Luherne, E., Réveillac, E., Ponsero, A., Sturbois, A., Ballu, S., Perdriau, M., Le Pape, O., 2016. Fish community responses to green tides in shallow estuarine and coastal areas. Estuarine. Coastal and Shelf Science 175, 79-92. https://doi.org/10.1016/j.ecss. 2016.03.031.

Li, Y., Song, W., Xiao, J., Wang, Z.L., Fu, M.Z., Zhu, M.Y., Li, R.X., Zhang, X.L., Wang, X.N., 2014. Tempo-spatial distribution and species diversity of green algae micropropagules in the Yellow Sea during the large-scale green tide development. Harmful Algae 39, 40-47. https://doi.org/10.1016/j.hal.2014.05.013.

Liu, D.y., Keesing, J.K., Dong, Z.J., Zhen, Y., Di, B.P., Shi, Y.J., Fearns, P., Shi, P., 2010. Recurrence of the world's largest green-tide in 2009 in Yellow Sea, China: Porphyra yezoensis aquaculture rafts confirmed as nursery for macroalgal blooms. Mar. Pollut. Bull. 60, 1423-1432. https://doi.org/10.1016/j.marpolbul.2010.05.015.

Liu, D.Y., Keesing, J.K., He, P.M., Wang, Z.L., Shi, Y.J., Wang, Y.J., 2013. The world's largest macroalgal bloom in the Yellow Sea, China: formation and implications. Estuar. Coast Shelf Sci. 129, 2-10. https://doi.org/10.1016/j.ecss.2013.05.021.

Liu, X.Q., Li, Y., Wang, Z.L., Zhang, Q.C., Cai, X.Q., 2015. Cruise observation of Ulva prolifera bloom in the southern Yellow Sea, China. Estuar. Coast Shelf Sci. 163, 17-22. https://doi.org/10.1016/j.ecss.2014.09.014.

Lotze, H.K., Schramm, W., Schories, D., Worm, B., 1999. Control of macroalgal blooms at early developmental stages: pilayella littoralis versus Enteromorpha spp. Oecologia 119, 46-54. https://doi.org/10.1007/s004420050759.

Marine Environmental Protection Department of North China Sea Branch of State Oceanic Administration, 2018. Green Tide Bulletin in North China Sea. 1 Jan 2018. http:/ 123.234.129.76:8088/search1/WebSite/cms/SearchInfoList.aspx? searchContent $=\%$ $\mathrm{E} 7 \% \mathrm{BB} \% \mathrm{BF} \% \mathrm{E} 6 \% \mathrm{BD} \% \mathrm{AE}$ (In Chinese).

Merceron, Michel, Antoine, Virginie, Auby, Isabelle, Morand, Philippe, 2007. In situ growth potential of the subtidal part of green tide forming Ulva spp. stocks. Sci. Total Environ. 384, 293-305. https://doi.org/10.1016/j.scitotenv.2007.05.007.

Paumier, A., Tatlian, T., Réveillac, E., Le Luherne, E., Ballu, S., Lepage, M., Le Pape, O., 2018. Impacts of green tides on estuarine fish assemblages. Estuarine. Coastal and Shelf Science 213, 176-184. https://doi.org/10.1016/j.ecss.2018.08.021.

Qiao, F.L., Wang, G.S., Lue, X.G., Dai, D.J., 2011. Drift characteristics of green macroalgae in the Yellow Sea in 2008 and 2010. Chin. Sci. Bull. 56, 2236-2242. https:// doi.org/10.1007/s11434-011-4551-7.

Qiu, Y.H., Lu, J.B., 2015. Advances in the monitoring of Enteromorpha prolifera using remote sensing. Acta Ecol. Sin. 35, 4977-4985. (In Chinese with English abstract). https://doi.org/10.5846/stxb201309232339.

Rouse Jr., J.W., Haas, R.H., Schell, J.A., Deering, D.W., 1974. Monitoring vegetation systems in the great plains with ERTS. In: 3rd Earth Resources Technology Satellite-1
Symposium. NASA, Washington, D.C., pp. 309-317.

Sina, 2018. Ulva Prolifera Drift to Weihai Sea and All Parties Join Hands to Clean up the Sea Area. 13 Aug 2018. http://k.sina.com.cn/article_3579657682_ d55d3dd200100cht9.html (In Chinese).

Son, Y.B., Choi, B.J., Kim, Y.H., Park, Y.G., 2015. Tracing floating green algae blooms in the Yellow Sea and the East China Sea using GOCI satellite data and Lagrangian transport simulations. Remote Sens. Environ. 156, 21-33. https://doi.org/10.1016/j. rse.2014.09.024.

Song, D.B., Gao, Z.Q., Xu, F.X., Zheng, X.Y., Ai, J.Q., Chen, M.S., 2017. Remote sensing of the Yellow Sea green tide in 2014 based on GOCI. In: Remote Sensing and Modeling of Ecosystems for Sustainability XIV. Spie-Int Soc Optical Engineering, Bellingham. https://doi.org/10.1117/12.2272518.

Wei, Q.S., Yu, Z.G., Ran, X.B., Zang, J.Y., 2011. Characteristics of the western coastal current of the Yellow Sea and its impacts on material transportation. Adv. Earth Sci. 26, 145-156 (In Chinese with English abstract).

Xing, Q.G., Zheng, X.Y., Shi, P., Hao, J.J., Yu, D.F., Liang, S.Z., Liu, D.Y., Zhang, Y.Z. 2011. Monitoring "green tide" in the Yellow Sea and the east China sea using multitemporal and multi-source remote sensing images. Spectrosc. Spectr. Anal. 31, 1644-1647. (In Chinese). https://doi.org/10.3964/j.issn.1000-0593(2011)061644-04.

Xing, Qianguo, Wu, Lingling, Tian, Liqiao, Cui, Tingwei, Li, Lin, Kong, Fanzhou, Gao, Xuelu, Wu, Mengquan, 2018. Remote sensing of early-stage green tide in the Yellow Sea for floating-macroalgae collecting campaign. Mar. Pollut. Bull. 133, 150-156. https://doi.org/10.1016/j.marpolbul.2018.05.035.

Xinhua News Agency, 2015. Sporadic Green Tide of Enteromorpha Prolifera Have Appeared in Some Coastal Waters of Shandong Province. 2015-6-24. (In Chinese). http://www.gov.cn/xinwen/2015-06/24/content 2883437.htm.

Ye, N.H., Zhang, X.W., Mao, Y.Z., Liang, C.W., Xu, D., Zou, J., Zhuang, Z.M., Wang, Q.Y., 2011. 'Green tides' are overwhelming the coastline of our blue planet: taking the world's largest example. Ecol. Res. 26, 477-485. https://doi.org/10.1007/s11284 011-0821-8.

Yu, R.C., Liu, D.Y., 2016. Harmful algal blooms in the coastal waters of China: current situation, long-term changes and prevention strategies. Bull. Chin. Acad. Sci. 31, 1167-1174. (In Chinese with English Abstract). https://doi.org/10.16418/j.issn. 1000-3045.2016.10.005.

Zhang, J.H., Huo, Y.Z., Zhang, Z.L., Yu, K.F., He, Q., Zhang, L.H., Yang, L.L., Xu, R., He, P.M., 2013. Variations of morphology and photosynthetic performances of Ulva prolifera during the whole green tide blooming process in the Yellow Sea. Mar. Environ. Res. 92, 35-42. https://doi.org/10.1016/j.marenvres.2013.08.009.

Zhang, J.H., Zhao, P., Huo, Y.Z., Yu, K.F., He, P.M., 2017. The fast expansion of Pyropia aquaculture in "Sansha" regions should be mainly responsible for the Ulva blooms in Yellow Sea. Estuar. Coast Shelf Sci. 189, 58-65. https://doi.org/10.1016/j.ecss.2017. 03.011.

Zhang, Q.C., Kong, F.Z., Yan, T., Yu, R.C., Hu, X.K., Miao, H., Zhou, M.J., 2018, Green algae detached from aquaculture rafts into seawater resulted in green tide occurrence in the yellow sea. Oceanol. Limnol. Sinica 49, 1014-1020. (In Chinese with English abstract). https://doi.org/10.11693/hyhz20180400076.

Zhao, J., Jiang, P., Liu, Z.Y., Wei, W., Lin, H.Z., Li, F.C., Wang, J.F., Qin, S., 2013. The yellow sea green tides were dominated by one species, Ulva (Enteromorpha) prolifera, from 2007 to 2011. Chin. Sci. Bull. 58, 2298-2302. https://doi.org/10.1007/ s11434-012-5441-3.

Zhao, J., Jiang, P., Qin, S., Liu, X.j., Liu, Z.Y., Lin, H.Z., Li, F.C., Chen, H.X., Wu, C.H., 2015. Genetic analyses of floating Ulva prolifera in the Yellow Sea suggest a unique ecotype. Estuar. Coast Shelf Sci. 163, 96-102. https://doi.org/10.1016/j.ecss.2015. 05.027.

Zheng, X.Y., Gao, Z.Q., Ning, J.C., Xu, F.X., Liu, C.S., Sun, Z.B., 2016. Remote sensing monitoring of green tide in the Yellow Sea in 2015 based on GF-1 WFV data. In: Remote Sensing and Modeling of Ecosystems for Sustainability Xiii. Spie-Int Soc Optical Engineering, Bellingham. https://doi.org/10.1117/12.2235833.

Zhou, M.J., Liu, D.Y., Anderson, D.M., Valiela, I., 2015. Introduction to the special issue on green tides in the Yellow Sea. Estuar. Coast Shelf Sci. 163, 3-8. https://doi.org/10 1016/j.ecss.2015.06.023. 